\title{
ISOLATION AND ANTIBIOTIC SENSITIVITY PATTERN OF CITROBACTER SPECIES WITH ESBL AND AMPC DETECTION AT TERTIARY CARE HOSPITAL, BANGALORE
}

\author{
Priyadarshini', Kasukurthy Leela Rani², Rajendran Ramaswamy33 \\ ${ }_{1}^{1}$ Post Graduate Student, Department of Microbiology, Vydehi Institute of Medical Sciences and Research Centre, Bangalore. \\ ${ }^{2}$ Associate Professor, Department of Microbiology, Vydehi Institute of Medical Sciences and Research Centre, Bangalore. \\ 3Professor \& HOD, Department of Microbiology, Vydehi Institute of Medical Sciences and Research Centre, Bangalore.
}

\begin{tabular}{l} 
ABSTRACT \\
\hline BACKGROUND \\
Genus Citrobacter is one of the aerobic Gram negative non-sporing bacilli, from the Enterobacteriaceae family. Citrobacter \\
koseri and Citrobacter freundii are the commonest species implicated in infections. It is emerging as an important nosocomial \\
pathogen. It is associated with high mortality and morbidity rate. They are often resistant to routinely used antibiotics. Emerging \\
drug resistance is a therapeutic concern for clinicians worldwide, thus isolation and antibiotic sensitivity of Citrobacter is critically \\
needed.
\end{tabular}

\section{OBJECTIVES}

Identification of Citrobacter species and antibiotic sensitivity pattern with AmpC and ESBL Detection.

\section{METHODS}

Prospective study was done from June 2014 to March 2015. The samples were collected from patients attending VIMS and RC. The samples were processed and identified by standard protocol. Citrobacter isolates were tested for antibiotic sensitivity by Kirby-Bauer disc diffusion method as per clinical and standard institute guidelines. Detection of AmpC by Cephamycin Hodge test using Cefoxitin $30 \mu \mathrm{g}$ with ATCC strains of Escherichia coli 25922 was done. ESBL detection was done by Ceftazidime (30 $\mu \mathrm{g})$ and Ceftazidime/clavulanic acid (30 $\mu \mathrm{g} / 10 \mu \mathrm{g}$ ) and Cefotaxime (30 ug) Cefotaxime/clavulanic acid (30 ug/10 ug).

\section{RESULTS}

Out of 5695 Gram negative isolates identified, 690 were Citrobacter isolates. Citrobacter koseri 398 (62.5\%) and Citrobacter freundii $292(37.5 \%)$ were the commonest species isolated. The antibiogram as per CLSI Guidelines showed resistance to Fluoroquinolones, Cephalosporins and beta lactamase inhibitors. Carbapenems were found to be sensitive. The resistance to beta lactamase inhibitors increased with the presence of AmpC beta lactamase (76\%) and ESBL (50\%).

\section{CONCLUSION}

Citrobacter species are emerging as an important nosocomial pathogen. Citrobacter koseri and Citrobacter freundii were the commonest species isolated. Antibiogram showing an increase in resistance among the beta lactamase inhibitors, Cephalosporins and sensitive to Carbapenems, so indiscriminate use of broad-spectrum antibiotics should be avoided and use of Carbapenems should be kept as a reserve drug. Detection of drug resistance in Citrobacter spp. will help in empirical therapy and prevent spread of infection by resistant strains.

\section{KEYWORDS}

Citrobacter, ESBL, Amp C.

HOW TO CITE THIS ARTICLE: Priyadarshini, Rani KL, Ramaswamy R. Isolation and antibiotic sensitivity pattern of citrobacter species with ESBL and AmpC detection at Tertiary Care Hospital, Bangalore. J. Evolution Med. Dent. Sci. 2016;5(30):1553-1556, DOI: $10.14260 /$ jemds/2016/365

\section{INTRODUCTION}

Genus Citrobacter is a facultative Gram negative bacilli which belongs to Enterobacteriaceae family. These organisms were commonly isolated from variety of clinical samples like pus, sputum, urine, blood, catheter tip, tracheal aspirate.

Financial or Other, Competing Interest: None.

Submission 07-10-2015, Peer Review 20-03-2016,

Acceptance 25-03-2016, Published 13-04-2016.

Corresponding Author:

Dr. Kasukurthy Leela Rani,

Associate Professor,

Department of Microbiology,

Vydehi Institute of Medical Sciences and Research Centre,

Bangalore-66.

E-mail: leela.kasukurthy@yahoo.in

DOI: $10.14260 /$ jemds $/ 2016 / 365$
Citrobacter species are emerging as important nosocomial pathogen with multidrug resistance, which is leading to high mortality rate. $1,2,3$

Although, Citrobacter spp. are infrequent nosocomial pathogens, a local or systemic breech in the host defence can allow them to cause a range of infections. 4

It was commonly isolated from urinary tract infections, neonatal sepsis, pulmonary infections, brain abscess, meningitis and blood stream infections. Citrobacter koseri causes meningitis and brain abscess in neonates. Citrobacter freundii commonly isolated from urinary and respiratory tract infections. Citrobacter sedlakii, which causes sepsis meningitis and brain abscess. ${ }^{5}$

They are resistant to routinely used antibiotics, especially the extended spectrum Cephalosporins, due to 
over expression of chromosomal and plasmid-mediated betalactamases.

In recent years extended spectrum beta lactamases have become more and more prevalent in species characterized by inducible class $\mathrm{C}$ Cephalosporins (AmpC) and ESBL.

\section{AIMS AND OBJECTIVES}

1. To isolate and identify Citrobacter species.

2. Detection of multidrug resistance with AmpC and ESBL.

\section{MATERIALS AND METHODS}

The present study was conducted in the Microbiology Department of Vydehi Institute of Medical Sciences and Research Centre, Bangalore, during June 2014 to March 2015. A total of 5695 Gram negative isolates were recovered from different clinical samples like pus, urine, sputum, catheter tip, tracheal aspirate and blood. The samples were collected from different outpatient department and wards like Surgery, Medicine, Orthopaedic, MICU, Neonatal ICU, Paediatric, ENT, OBG. The isolates of the Citrobacter species were further identified by their colony characteristics, Gram staining and biochemical reactions by standard protocols. The antibiotic sensitivity testing of Citrobacter species was performed on Mueller Hinton Agar by disc diffusion technique and the results were interpreted as per clinical standard laboratory institute guidelines. ${ }^{6}$

Antimicrobials used were Ampicillin $(10 \mu \mathrm{g})$, Amoxyclav $(20 / 10 \mu \mathrm{g})$, Tetracycline $(30 \mu \mathrm{g})$, Cotrimoxazole $(1.25 \mu \mathrm{g}$ Trimethoprim/23.75 $\mu \mathrm{g}$ sulfamethoxazole), Gentamicin (10 $\mu \mathrm{g})$, Ciprofloxacin $(5 \mu \mathrm{g})$, Cephalexin $(30 \mu \mathrm{g})$, Amikacin (30 $\mu \mathrm{g})$, Ceftazidime $(30 \mu \mathrm{g})$, Piperacillin/Tazobactam (100 $\mu \mathrm{g} / 10 \mu \mathrm{g})$, Norfloxacin $(10 \mu \mathrm{g})$, Nitrofurantoin $(300 \mu \mathrm{g})$,
Ceftazidime/clavulanic (30 $\mu \mathrm{g} / 10 \mu \mathrm{g}$ ), Imipenem (10 ug), Meropenem (5 $\mu \mathrm{g})$, Cefoperazone/sulbactam $(30 \mu \mathrm{g} / 10 \mu \mathrm{g})$.

The discs were obtained from HiMedia Laboratories. Standard strains of Escherichia coli ATCC 25922, Staphylococcus aureus ATCC 25923 and Pseudomonas aeruginosa ATCC 27853 were used as controls. Detection of AmpC was done Cephamycin Hodge test by using Cefoxitin disc $(30 \mu \mathrm{g})$ with ATCC Strains of Escherichia coli 25922. Detection of extended spectrum beta lactamases was done by using Ceftazidime $(30 \mu \mathrm{g})$ and Ceftazidime $(30 \mu \mathrm{g}) /$ Clavulanic acid $(10 \mu \mathrm{g})$ and Cefotaxime $(30 \mu \mathrm{g})$ and Cefotaxime (30 $\mu \mathrm{g}) /$ Clavulanic acid $(10 \mu \mathrm{g})$.

\section{RESULTS}

Out of 5695 Gram negative isolates, 690 were Citrobacter species, of which Citrobacter koseri were 398 (62.5\%) and Citrobacter freundii were 292 (37.5\%).

The mean age was $40 \mathrm{yrs}$.

\begin{tabular}{|c|c|}
\hline TOTAL & $\mathbf{6 9 0}$ \\
\hline CITROBACTER KOSERI & $398(62.5 \%)$ \\
\hline CITROBACTER FREUNDII & $292(37.5 \%)$ \\
\hline \multicolumn{2}{|c|}{ Table 1: Percentage of Citrobacter Species } \\
\hline
\end{tabular}

Percentage of citrobacter isolated from various clinical samples and percentage of clinical samples from various wards are shown in Table 2 and 3.

\begin{tabular}{|c|c|c|c|c|c|}
\hline Pus & Sputum & Urine & $\begin{array}{c}\text { Catheter } \\
\text {-tip }\end{array}$ & $\begin{array}{c}\text { Tracheal } \\
\text { Aspirate }\end{array}$ & Blood \\
\hline $28 \%$ & $27 \%$ & $25 \%$ & $8 \%$ & $7 \%$ & $5 \%$ \\
\hline
\end{tabular}

Table 2: Percentage of Commonly Isolated Samples

\begin{tabular}{|c|c|c|c|c|c|c|}
\hline Surgery & Medicine & Orthopaedic & MICU & NICU & Paediatric & ENT \\
\hline $38 \%$ & $18 \%$ & $12 \%$ & $11 \%$ & $9 \%$ & $8 \%$ \\
\hline \multicolumn{7}{|c|}{ Table 3: Percentage of Samples from Various Wards } \\
\hline
\end{tabular}

Percentage of antibiotic sensitivity and resistance of citrobacter is shown in Table 4.

\begin{tabular}{|c|c|c|}
\hline ANTIBIOTICS & SENSITIVITY & RESISTANCE \\
\hline CEFTAZIDIME/CLAVULANIC & $47 \%$ & $53 \%$ \\
\hline CEFOPERAZONE/SULBACTAM & $49 \%$ & $51 \%$ \\
\hline IMIPENEM & $98 \%$ & $2 \%$ \\
\hline MEROPENEM & $98 \%$ & $2 \%$ \\
\hline PIPERACILLIN/TAZOBACTAM & $50 \%$ & $50 \%$ \\
\hline CEFOXITIN & $30 \%$ & $70 \%$ \\
\hline CEPHALEXIN & $21 \%$ & $79 \%$ \\
\hline CEFTAZIDIME & $31 \%$ & $69 \%$ \\
\hline CIPROFLOXACIN & $30 \%$ & $70 \%$ \\
\hline NORFLOXACIN & $30 \%$ & $70 \%$ \\
\hline GENTAMICIN & $31 \%$ & $69 \%$ \\
\hline TETRACYCLINE & $40 \%$ & $60 \%$ \\
\hline AMIKACIN & $40 \%$ & $60 \%$ \\
\hline COTRIMOXAZOLE & $38 \%$ & $62 \%$ \\
\hline NITROFURANTOIN & $63 \%$ & $37 \%$ \\
\hline CEFOTAXIME & $33 \%$ & $67 \%$ \\
\hline AMPICILLIN & $37 \%$ & $63 \%$ \\
\hline AMOXYCLAV & $39 \%$ & $61 \%$ \\
\hline
\end{tabular}

The antibiotic sensitivity according to CLSI guidelines showed resistant to Cephalexin (79\%), Cefoxitin (70\%), Norfloxacin (70\%), Nitrofurantoin (67\%), Ampicillin (63\%), Amoxyclav (61\%), Cotrimoxazole (62\%), Ciprofloxacin (70\%), Ceftazidime (69\%), Cefotaxime (67\%), Amikacin (60\%), Gentamicin (69\%), Tetracycline (60\%), Piperacillin/tazobactam (50\%), Cefoperazone-sulbactam (51\%), Ceftazidime Clavulanic acid (53\%), Imipenem (2\%). Citrobacter was resistant to Cephalosporins, Fluoroquinolones and $\beta$ Lactamase Inhibitors and sensitive to Carbapenems.

The third generation extended spectrum Cephalosporins, which were resistant were further processed. Cephamycin Hodge test was performed by using $30 \mu \mathrm{g}$ Cefoxitin disc. The Mueller Hinton agar plate was swabbed with ATCC strains of Escherichia coli 25922 of $0.5 \%$ McFarland and Cefoxitin disc $(30 \mu \mathrm{g})$ was placed in the centre of the plate. AmpC positive strain of Klebsiella pneumoniae 700603 and negative (NonESBL producer of Escherichia coli ATCC 25922) was streaked from the disc to the edge of plate.

Test strains were streaked in a straight line from the edge of the disc to edge of the plate. After $24 \mathrm{hrs}$. Cephamycin Hodge test positive strains showed clover leaf like 
indentation of the Escherichia coli 25922 growing along the test organism growth streak within the disc diffusion (Fig. 1).

ESBL (Extended spectrum beta lactamases) was resistance to Penicillins, Beta Lactams, third generation Cephalosporin and Monobactams.

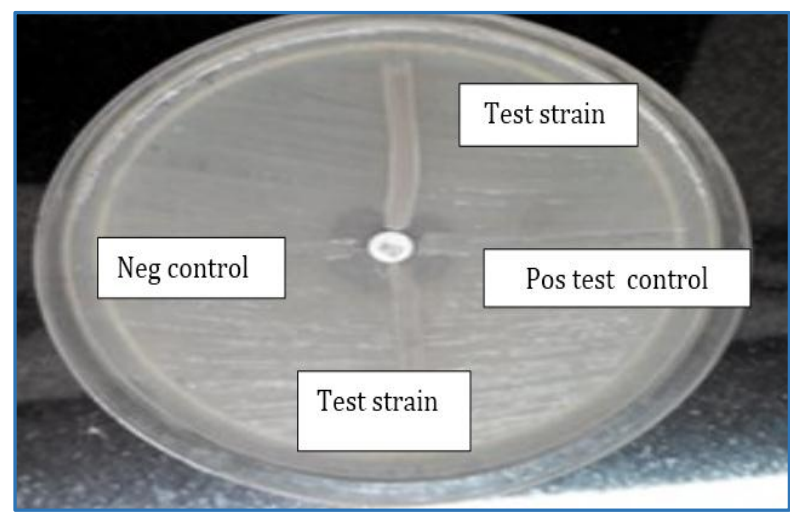

Fig. 1: Cephamycin Hodge Test AmpC Detection with Cefoxitin Disc and ATCC E. coli

ESBL detection was done by using Mueller Hinton agar plate and Cefotaxime $(30 \mu \mathrm{g})$, Cefotaxime clavulanic acid $(30 / 10 \mu \mathrm{g})$ and Ceftazidime $(30 \mu \mathrm{g})$, Ceftazidime clavulanic acid $(30 / 10 \mu \mathrm{g})$ placed at $20 \mathrm{~mm}$ distance apart; there was increase in zone size of more than $5 \mathrm{~mm}$ of either antimicrobial agent tested in combination with clavulanate vs the zone diameter of the agent when tested alone. (Fig. 2) The guidelines followed as per Clinical Standard Institute Guidelines. ${ }^{6}$ AmpC producers were $30 \%$ and ESBL producers were $35 \%$.

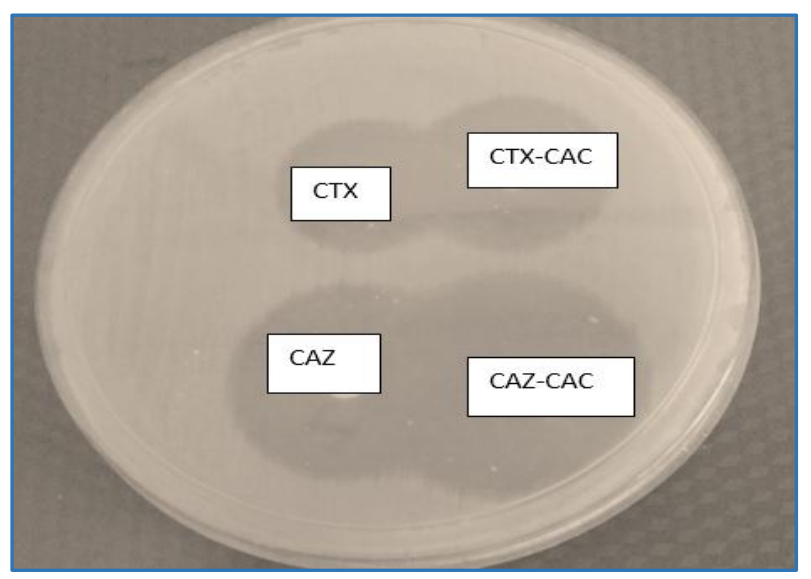

Fig. 2: ESBL Detection

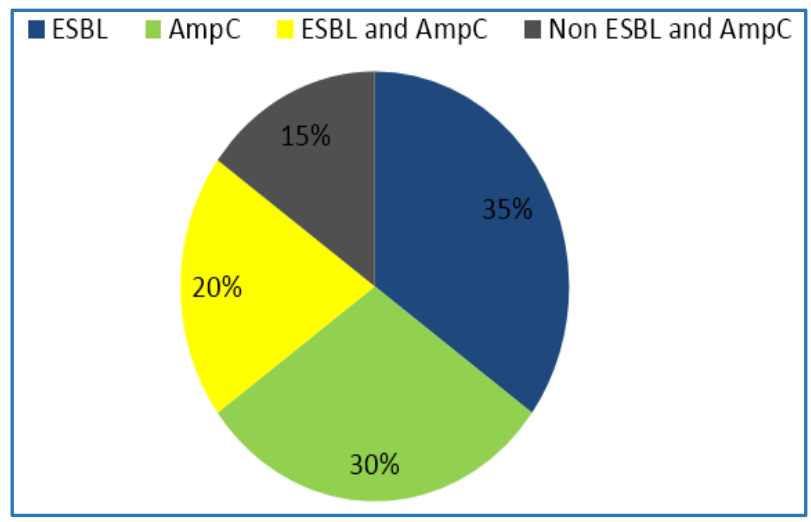

Fig. 3: Percentage of ESBL and AmpC
ESBL showed 15\%, AmpC 30\%, ESBL and AmpC 20\%, Non-ESBL and AmpC 15\% (Fig. 3).

\section{DISCUSSION}

In this study, Citrobacter species was commonly isolated from Surgery MICU, ICU and Emergency ward suggesting the hospital acquired infection. It was commonly seen in elderly and critically ill patients, which showed reduced immunity among these people. This was similar study seen in B Thapa et al. 2009.1

Out of 690 isolates, 398 were Citrobacter koseri was commonly identified, then followed by Citrobacter freundii as identified by Ashish Kanna et al. ${ }^{2}$ The commonly isolated samples were pus, sputum, urine, catheter tip and tracheal aspirate and blood. Majority of isolates were recovered from pus $38 \%$, urine $25 \%$, sputum $17 \%$ as reported by Basavaraj et al. pus $48 \%$, urine $24 \%$, sputum $20 \%$. $^{3}$

Citrobacter koseri was commonly isolated from urine sample from critically ill and debilitated patients suggesting chronic urinary catheter related infections as seen in Ranjan et al. ${ }^{4}$

Antibiotic susceptibility pattern showed sensitivity to Carbapenems (98\%). Resistance to third generation Cephalosporins (70\%), Piperacillin Tazobactam (50\%) as seen in Basavaraj et al., sensitive to Carbapenems (91.8\%), resistant to third generation Cephalosporins (76.4\%), Piperacillin Tazobactam (41.7\%). ${ }^{3}$ There was increase in resistance to Beta Lactam inhibitors and third generation Cephalosporins.

ESBL producers among Citrobacter species was 35\% by double disc synergy method using Cefotaxime $30 \mu \mathrm{g}$ and Ceftazidime $30 \mu \mathrm{g}$ and combination drug Cefotaxime $30 \mu \mathrm{g}$ and Clavulanic acid $10 \mu \mathrm{g}$ and Ceftazidime $30 \mu \mathrm{g}$ and Clavulanic acid $10 \mu \mathrm{g}$. The rate of ESBL production among Citrobacter species was higher as compared to Shobha et al. and Mehar Rizvi et al. 2009.7,8

The AmpC producers among Citrobacter species was $30 \%$ as compared to Mehar Rizvi $29 \%{ }^{7}$

In this study, maximum sensitivity was observed with Imipenem $98 \%$ as compared with other studies, but this drug should not be used indiscriminately and should be kept as reserve drug as otherwise resistance to this drug may cause a threat to treatment.

In patients with immunodeficiency, multiple trauma or with surgical interventions or with implants, antibiotic treatment regime should be well planned to prevent the drug resistance as these patients strains are more at risk for MDR Strains, ESBL and AmpC.., 10

\section{CONCLUSION}

Citrobacter species are emerging as important nosocomial pathogen. Citrobacter koseri and Citrobacter freundii were the commonest species isolated. Antibiogram showing an increase in resistance among the $\beta$ lactamase drugs, (Penicillins, Extended Spectrum Cephalosporins, $\beta$ lactamase inhibitors and Monobactams). ${ }^{11}$ Phenotypic detection of ESBL and AmpC though not confirmatory is faster, more cost effective, less labour intensive and does not require a high level of technical expert. It is therefore easier to perform on a daily basis, not only in resource poor countries, but also in developed countries. The outcome of phenotypic detection of resistance mechanism undoubtedly will be better patient 
care. ${ }^{12}$ Detection of drug resistance in Citrobacter species will help in empirical therapy and prevent spread of infection by resistant strains. ${ }^{13}$

\section{REFERENCES}

1. Thapa $\mathrm{B}$, Adhikari $\mathrm{P}, \mathrm{Mahat} \mathrm{K}$, et al. Multidrug resistant nosocomial citrobacter in a hospital in Kathmandu. Nepal med coll J 2009;11(3):195-99.

2. Ashish K, Nachatar S, Menka K. The antibiotic resistance pattern in citrobacter species: an emerging nosocomial pathogen in a tertiary care hospital. J Clin Diag Res 2012;6(4):642-44.

3. Metri BC, Jyothi P, Peerapur BV. Antimicrobial resistance profile of citrobacter species in a tertiary care hospital of southern India. Ind $\mathrm{J}$ Med Sci 2011;65(10):429-35.

4. Ranjan KP, Ranjan N. Citrobacter: an emerging health care associated urinary pathogen. Urology Annals 2013;5(4):313-14.

5. Konemann EW, Allen SD, Janda WM, et al. Colour, atlas and textbook of diagnostic microbiology, philadelphia: JB lippincott company, 2006; $6^{\text {th }}$ ed:171-252.

6. Clinical and Laboratory Standard Institute. Performance standards for antimicrobial susceptibility testing; twenty first informational supplement, CLSI document, Wayne, PA 2011;CLSI:M100-S21.
7. Rizvi M, Fatima N, Rashid M, et al. Extended spectrum amp $\mathrm{C}$ and metallo-beta-lactamases in serratia and citrobacter spp in a disc approximation assay. J Infect Dev Ctries 2009;3(4):285-94.

8. Shobha KL, Akshatha SJ, Sonam GSA, et al. Antimicrobial susceptibility pattern of urinary tract isolates of citrobacter species in a tertiary care hospital. Inter J of Pharmacol Toxicol 2014;57(3):439-41.

9. Mohan S, Agarwal J, Srivastava R, et al. Observations on citrobacter species from a tertiary care health centre with special reference to multidrug resistance and presence of CTX-M gene. Ind J of Pathol Microbiol 2014;57(3):439-41.

10. Rizvi M, Fatima N, Shukla I. Epidemiology of the extended spectrum beta lactamases in the serratia and citrobacter species in north India. Ind J of Pathol and Microbiol 2010;53(1):193-94.

11. Kargar M, Kargar M, Jahromi MZ. Molecular detection of ESBLs production and antibiotic resistance patterns in gram negative bacilli isolated from urinary tract infections. Ind J of Pathol Microbiol 2014;57(2):244-48.

12. Hung KH, Yan JJ, Lu JJ. Characterization of the modified hodge test-positive isolates of enterobacteriaceae in Taiwan. J Microbiol Immunol Infect 2013;46(1):35-40.

13. Mohanty S, Singhal R, Sood S, et al. Citrobacter infections in a tertiary care hospital in northern India. J Infect 2007;54(1):58-64. 